\title{
Molecular Diagnosis of Human Metapneumovirus in Hospitalized Children with Acute Respiratory Tract Infections using RT-LAMP: A Population-Based Prospective Study
}

\author{
Ahmed Osman Gasim Attar ${ }^{1}$, Khalid Enan ${ }^{2}$, Sara Abdelghani ${ }^{3}$, Lienda Bashier Eltayeb ${ }^{4 *}$ \\ ${ }^{1}$ Department of Medical Microbiology, Faculty of Medical Laboratory Sciences, \\ Al-Neelain University, Khartoum, Sudan \\ ${ }^{2}$ Department of Virology, Central Laboratory of the Ministry of Higher Education and Scientific Research, \\ Khartoum, Sudan \\ ${ }^{3}$ Department of Parasitology, Faculty of Medical Laboratory Sciences, \\ Al-Neelain University, Khartoum, Sudan \\ ${ }^{4}$ Department of Medical Laboratory Science, College of Applied Medical Science, \\ Prince Sattam bin Abdulaziz University, Al-Kharj, Saudi Arabia
}

\begin{abstract}
Background: Human metapneumovirus (hMPV) is a major novel cause of acute respiratory infections ranging from wheezing to bronchiolitis and pneumonia in children worldwide. The aim of this study was to detect hMPV in hospitalized children with acute respiratory tract infections (ARTIs) by using reverse transcription-loop mediated isothermal amplification (RT-LAMP) assay.

Methods and Results: A total of 68 children with ARTIs who were clinically suspected of acquiring hMPV were included in the study in the period between January 2019 and February 2020. Posterior-pharyngeal (throat) swabs were obtained from each patient. hMPV RNA was revealed in $18(26.5 \%)$ cases. The age range was from $<1$ year to 10 years (mean age of 5.25 \pm 2.62 ). Sixteen $(23.5 \%)$ of the participants were in the age group of $<1$ year, where the majority of hMPV-positive subjects $(\mathrm{n}=11)$ were found $(16.2 \%$ of the total number of infected children) $(P=0.0025)$. The majority of hMPV-negative subjects $(\mathrm{n}=15)$ were found in the age group of 5-10 years (22\% of the total number of infected children) $(P=0.0025)$. Cough, fever, and shortness of breath were common symptoms in hMPV-positive children: 15(83.3\%), 13(72.2\%), and 12(66.7\%), respectively. There was a statistically significant correlation between common clinical symptoms and the age group of hMPV-positive children: symptoms were common in the age group of $<1$ year.

Conclusion: Our study represents the first report in Khartoum, Sudan, on the detection of hMPV using RT-LAMP. RT-LAMP is a valuable, quick diagnostic technique for hMPV detection. (International Journal of Biomedicine. 2021;11(2):146-150.)
\end{abstract}

Key Words: human metapneumovirus • acute respiratory tract infections $\bullet$ RT-LAMP

For citation: Attar AOG, Enan Kh, Abdelghani S, Eltayeb, LB. Molecular Diagnosis of Human Metapneumovirus in Hospitalized Children with Acute Respiratory Tract Infections using RT-LAMP: A Population-Based Prospective Study. International Journal of Biomedicine. 2021;11(2):146-150. doi:10.21103/Article11(2)_OA4

\section{Introduction}

Human metapneumovirus (hMPV) is a major novel cause of acute respiratory infections ranging from wheezing to bronchiolitis and pneumonia in children worldwide. hMPV is a member of the Paramyxoviridae family of viruses. The hMPV genome is a negative-sense, single-stranded RNA molecule, $13.3 \mathrm{~Kb}$ long, encoding eight proteins. ${ }^{(1)}$ Three surface proteins (F-fusion, G-attachment glycoprotein, and SH-small hydrophobic) are encoded within the hMPV genome. ${ }^{(2)}$ The Fand G-nucleotide sequences have been largely used to study hMPV genetic variation. ${ }^{(3)}$ The $h M P V G$ gene shows higher 
sequence and amino acid diversity. ${ }^{(4,5)}$ The highly conserved $\mathrm{F}$ protein constitutes an antigenic determinant that mediates cross-lineage neutralization and protection. . $^{(1,6)}$

hMPV was first identified in the Netherlands by Hoogen et al. ${ }^{(7)}$ hMPV has currently been detected in Europe, America, Australia, Asia, and Africa. ${ }^{(8-10)} \mathrm{hMPV}$ was first isolated from stored nasopharyngeal aspirates of infected children collected over a 20-year period. hMPV appears to have respiratory epithelium tropism. ${ }^{(11)}$ The symptoms of both upper and lower respiratory tract disease have been associated with hMPV infections in infants, young children, the elderly, and immunocompromized patients. However, at the age of five years, virtually every individual has experienced at least one hMPV infection. ${ }^{(12,13)}$ Different studies have noted that temperate regions are more prevalent for hMPV, which circulates mainly during the winter. ${ }^{(14-17)}$ Clinical symptoms of hMPV infection resemble those caused by respiratory syncytial virus and range from mild upper respiratory tract infections to wheezing and severe lower respiratory tract illnesses that require hospitalization. ${ }^{(18-20)}$ Although hMPV infections have been diagnosed in all age groups, the virus likely has its greatest effect on children. ${ }^{(21)}$ Several studies have demonstrated that hMPV accounts for a major proportion of hospitalizations for lower respiratory tract infections in infants and young children. The most frequent diagnoses in hospitalized children are bronchiolitis and pneumonia, but occasionally hMPV may also cause severe illnesses that require treatment at intensive care units. ${ }^{(24,25)}$

The aim of this study was to detect hMPV in hospitalized children with acute respiratory tract infections (ARTIs) by using reverse transcription-loop mediated isothermal amplification (RT-LAMP) assay.

\section{Materials and Methods}

This descriptive cross-sectional study was carried out in Mohammed El Amin Hamid Hospital for Children (MEHHC) in Omdurman (Khartoum State, Sudan), in the period between January 2019 and February 2020.

The study was conducted in accordance with ethical principles of the WMA Declaration of Helsinki (1964, ed. 2013) and approved by the Ethics Committee of Faculty of Medical Laboratory Sciences, Al-Neelain University. Informed consent was obtained from the children's parents or guardians.

A total of 68 children with ARTIs who were clinically suspected of acquiring hMPV were included in the study. Participants were enrolled in the study according to the following inclusion criteria: children between $<1$ to 10 years, of both sexes, hospitalized and suffering from ARTIs. All subjects with other respiratory diseases were excluded.

\section{Collection of Posterior-Pharyngeal (throat) Swabs}

Samples were obtained from each patient as described in the CDC's specimen collection guidelines. ${ }^{(26)}$ Using a tongue depressor, the investigator swabbed both the posterior pharynx and the tonsillar areas with a sterile nylon swab (Regular Flocked swabs, Copan Diagnostics Inc., Murrieta, California, USA), in the clockwise direction, and the swabs were withdrawn (without touching the tongue). The swabs were immediately placed in the virus transport medium. The collected samples were transported in an ice bag to the laboratory and stored at $-80^{\circ} \mathrm{C}$ until used.

\section{RT-LAMP reaction}

Throat samples in VTM were vortexed for 10 seconds, the obtained solution was used for RNA extraction, and the viral RNA was eluted in 30ul of elution buffer. Then RT-PCR was used to produce cDNA, which was finally eluted in $30 \mu \mathrm{l}$ of elution buffer and stored at $-20^{\circ} \mathrm{C}$.

For RT-LAMP, viral RNA was extracted from throat specimens with QIAamp Viral RNA Mini Kit (Qiagen, Germany) according to the manufacturer's instructions. Six primers, including two outer primers (F3 and B3), two inner primers (FIP [F1c +F2], BIP [B1c +B2]) and two loop primers (LF and LB), were used for hMPV N gene. ${ }^{(27)}$ The sequences of each primer are shown in Table 1. RT-LAMP reaction was performed according to Wang et al. ${ }^{(27)}$

Table 1.

Primer sets to detect hMPV N gene by RT-LAMP

\begin{tabular}{|l|l|}
\hline F3 & ACAGGAGTCTATTCATTGAGT \\
\hline B3 & ACCAAATCATAAACCTCTGTG \\
\hline FIP(F1c+F2) & $\begin{array}{l}\text { C G G C T C C ATA A G C T T G C A T A A AT AT- } \\
\text { GGGAAAGCTTTAGGCTCA }\end{array}$ \\
\hline BIP(B1c+B2) & $\begin{array}{l}\text { A C A A T G C T A A G G T G G G G T G T C - } \\
\text { CTTCAATTCAGCTTGCACAG }\end{array}$ \\
\hline LF & CAAACAAACTTTCTGCTTTGCTTCC \\
\hline LB & CATCTAACAACATAATGCTAGGGCA \\
\hline
\end{tabular}

Statistical analysis was performed using the IBM SPSS Statistics for Windows, Version 20.0. Armonk, NY: IBM Corp.). Baseline characteristics were summarized as frequencies and percentages for categorical variables. Group comparisons were performed using chi-square tests with Yates correction. A probability value of $P<0.05$ was considered statistically significant.

\section{Results}

The results of RT-LAMP for the diagnosis of hMPV in 68 throat swab samples collected from hospitalized children with ARTIs in Khartoum State are shown in Table 2. hMPV RNA was revealed in $18(26.5 \%)$ cases (Table 2).

Table 2.

The results of RT-LAMP for the diagnosis of $h M P V$

\begin{tabular}{|c|c|c|c|}
\hline RT-LAMP & Positive & Negative & Total \\
\hline hMPB RNA & $18(26.5) \%$ & $50(73.5) \%$ & $68(100 \%)$ \\
\hline
\end{tabular}

The age range was from $<1$ year to 10 years (mean age of $5.25 \pm 2.62)$. Sixteen $(23.5 \%)$ of the participants were in the age group of $<1$ year old, where the majority of hMPVpositive subjects $(n=11)$ were found $(16.2 \%$ of the total 
number of infected children) $(P=0.0025)$. The majority of hMPV-negative subjects $(n=15)$ were found in the age group of 5-10 years (22\% of the total number of infected children) $(P=0.0025)$ (Table 3$)$.

\section{Table 3.}

Frequency of hMPV among Hospitalized Children with ARTIs regarding their gender, fever, cough and $S O B$.

\begin{tabular}{|c|c|c|c|c|}
\hline Parameters & $\begin{array}{c}\text { Positive } \\
n=18\end{array}$ & $\begin{array}{c}\text { Negative } \\
\mathrm{n}=50\end{array}$ & $\begin{array}{l}\text { Total } \\
\mathrm{n}=68\end{array}$ & Statistics \\
\hline \multicolumn{5}{|c|}{ Gender } \\
\hline Male & $9(13.2 \%)$ & $23(33.8 \%)$ & $32(47 \%)$ & \multirow{2}{*}{$\begin{array}{l}\text { Chi-square: } \\
0.085 \\
P \text {-value: } 0.771\end{array}$} \\
\hline Female & $9(13.2 \%)$ & $27(39.7 \%)$ & $36(53 \%)$ & \\
\hline \multicolumn{5}{|c|}{ Age group } \\
\hline$<1$ & $11(16.2 \%)$ & $5(7.3 \%)$ & $16(23.5 \%)$ & \multirow{5}{*}{$\begin{array}{l}\text { Yates' chi-square: } \\
16.449 \\
\text { Yates' P-value: } \\
0.0025\end{array}$} \\
\hline $1-2.5$ & $2(3 \%)$ & $10(14.7 \%)$ & $12(17.6 \%)$ & \\
\hline $2.5-3.5$ & $1(1.5 \%)$ & $11(16.2 \%)$ & $12(17.6 \%)$ & \\
\hline $3.5-5$ & $3(4.4 \%)$ & $9(13.2 \%)$ & $12(17.6 \%)$ & \\
\hline $5-10$ & $1(1.5 \%)$ & $15(22 \%)$ & $16(23.5 \%)$ & \\
\hline
\end{tabular}

Cough, fever, and shortness of breath (SOB) were common symptoms in hMPV-positive children: 15(83.3\%), $13(72.2 \%)$, and $12(66.7 \%)$, respectively (Table 4$)$. There was a statistically significant correlation between common clinical symptoms and the age group of hMPV-positive children: symptoms were common in the age group of $<1$ year (Table 4 ).

Table 4.

Common clinical symptoms in the age groups of hMPV-positive subjects

\begin{tabular}{|l|c|c|c|}
\hline $\begin{array}{c}\text { Age group } \\
(\text { yrs })\end{array}$ & $\begin{array}{c}\text { Fever } \\
(\mathrm{n}=15)\end{array}$ & $\begin{array}{c}\text { Cough } \\
(\mathrm{n}=13)\end{array}$ & $\begin{array}{c}\text { SOB } \\
(\mathrm{n}=12)\end{array}$ \\
\hline$<1(\mathrm{n}=16)$ & $9(60.0)$ & $9(69.2 \%)$ & $9(75.0 \%)$ \\
\hline $\begin{array}{l}1-<2.5 \\
(\mathrm{n}=12)\end{array}$ & $2(13.3 \%)$ & $1(7.7 \%)$ & $1(8.3 \%)$ \\
\hline $\begin{array}{l}2.5-<3.5 \\
(\mathrm{n}=12)\end{array}$ & $1(6.7 \%)$ & $1(7.7 \%)$ & 0 \\
\hline $\begin{array}{l}3.5-<5 \\
(\mathrm{n}=12)\end{array}$ & $2(13.3 \%)$ & $1(7.7 \%)$ & $1(8.3 \%)$ \\
\hline $\begin{array}{l}5-10 \\
(\mathrm{n}=16)\end{array}$ & $1(6.7 \%)$ & $1(7.7 \%)$ & $1(8.3 \%)$ \\
\hline $\begin{array}{l}\text { Statistics } \\
11.137\end{array}$ & $\begin{array}{l}\text { Yates' } P \text {-value: } \\
0.0251\end{array}$ & $\begin{array}{l}\text { Yates' chi-square: } \\
0.0074 \text {-value: }\end{array}$ & $\begin{array}{l}\text { Yates' chi-square: } \\
0.969\end{array}$ \\
\hline
\end{tabular}

\section{Discussion}

The latest characterization of a new family member, which belongs to Paramyxoviridae, subfamily Pneumovirus, has provided a chance to assess the severity of the disease triggered by this previously unrecognized human pathogen. ${ }^{(28)}$ To the best of our knowledge, this is the first report on the detection of hMPV infection in Sudan using the RT-LAMP technique. In this study, hMPV has been shown to be responsible for a significant number of ARTIs in early infancy and childhood (26.5\%).

Regardless of the techniques used, different studies have concluded that hMPV infection occurs frequently early in childhood. ${ }^{(19,29,30)}$

The frequency of hMPV infections found in this study showed similarity and some variations with those that have emerged from previously published studies in different countries. ${ }^{(31,32)}$

These variations in incidence among studies might reflect different epidemiological patterns of hMPV infection in different countries, which in turn might be related to environmental factors, geographical factors, differences in host genetic susceptibility, sampling techniques, detection methods, and/or different viral strains circulating in different geographical areas. The use of RT-LAMP was particularly advantageous for hMPV because the virus is fastidious and difficult to grow in most cell lines. The newly established visual RT-LAMP assay is simple, efficient, cost-effective and convenient to use as a diagnostic tool in clinical practice. ${ }^{(27)}$

In our study, fever, cough, and dyspnea were the most significantly frequent clinical features among hMPV-positive children, while Wang et al. ${ }^{(33)}$ noted that fever, cough, and rhinorrhea were the main clinical manifestations; Papenburg et al. ${ }^{(34)}$ reported fever, dyspnea, wheezing, abnormal breathing sounds, and added that sounds were the most frequent clinical features among hMPV-positive children. This might reflect the broad spectrum of clinical diseases with different manifestations in hMPV infections, but all authors agreed that fever and cough are the most common clinical manifestations.

The study showed that hMPV infections were higher among age group $<1$ year $(16 \%)$ than among older children. This result was comparable to that of Zhang et al. ${ }^{(35)}$ and Wei et al. ${ }^{(36)}$ The higher incidence of hMPV infections among age group $<1$ year might signify the importance of this age group as a risk factor for infection.

Our findings are consistent with the results of Heikkinen et al. ${ }^{(37)}$ who revealed that the occurrence of hMPV infection in children $<2$ years of age was probably twice that in children 2-5 years of age and 10 times greater than in children $>9$ years of age. However, Papenburg reported comparable results that children $<6$ months are at risk of hMPV infection. ${ }^{(34)}$ These findings may be attributed to the immature immune system among pediatrics.

The results of our study showed that among hMPVpositive children, the male-to-female ratio was 1:1. Zuo et al. ${ }^{(38)}$ recorded results similar to the current study. Rein et al. found that of the 32 patients in whom hMPV was detected, 17(53.2\%) were female and 15(46.8\%) male. ${ }^{(39)}$ Most published studies reported no significant gender predominance.

\section{Limitations of the Study and Prospective}

The current study consisted of a total of only 68 participants (representativeness not achieved), so further investigation in different parts of the country with a larger sample size and cohort study design is indicated to highlight 
the severity of the problem. Moreover, it is necessary to include other variables, such as oxygen level and the existence of co-morbidities, as well as laboratory investigations, such as C-reactive protein level and complete blood count, which will help better management of the ARTIs caused by hMPV.

In conclusion, the study performed demonstrates that hMPV infection is significantly more severe in the age group of $<1$ year. Our study represents the first report in Khartoum, Sudan, on the detection of hMPV using RT-LAMP. RT-LAMP is a valuable, quick diagnostic technique for hMPV detection.

\section{Acknowledgments}

This study was supported by the Deanship of Scientific Research at Prince Sattam bin Abdulaziz University, AlKharj, Saudi Arabia. We would like to express our gratitude to the Faculty of Medical Laboratory Sciences at Al-Neelain University, Khartoum, Sudan.

\section{Competing Interests} interests.

The authors declare that they have no competing

\section{References}

1. van den Hoogen BG, Bestebroer TM, Osterhaus AD, Fouchier RA. Analysis of the genomic sequence of a human metapneumovirus. Virology. 2002 Mar 30;295(1):119-32. doi: 10.1006/viro.2001.1355.

2. Skiadopoulos MH, Biacchesi S, Buchholz UJ, AmaroCarambot E, Surman SR, Collins PL, Murphy BR. Individual contributions of the human metapneumovirus F, G, and $\mathrm{SH}$ surface glycoproteins to the induction of neutralizing antibodies and protective immunity. Virology. 2006 Feb 20;345(2):492-501. doi: 10.1016/j.virol.2005.10.016.

3. Banerjee S, Sullender WM, Choudekar A, John C, Tyagi V, Fowler K, Lefkowitz EJ, Broor S. Detection and genetic diversity of human metapneumovirus in hospitalized children with acute respiratory infections in India. J Med Virol. 2011 Oct;83(10):1799-810. doi: 10.1002/jmv.22176.

4. van den Hoogen BG, Herfst S, Sprong L, Cane PA, ForleoNeto E, de Swart RL, Osterhaus AD, Fouchier RA. Antigenic and genetic variability of human metapneumoviruses. Emerg Infect Dis. 2004 Apr;10(4):658-66. doi: 10.3201/ eid1004.030393.

5. Ishiguro N, Ebihara T, Endo R, Ma X, Kikuta H, Ishiko $\mathrm{H}$, Kobayashi K. High genetic diversity of the attachment (G) protein of human metapneumovirus. J Clin Microbiol. 2004 Aug;42(8):3406-14. doi: 10.1128/JCM.42.8.3406-3414.2004. 6. Schildgen V, van den Hoogen B, Fouchier R, Tripp RA, Alvarez R, Manoha C, et al. Human Metapneumovirus: lessons learned over the first decade. Clin Microbiol Rev. 2011 Oct;24(4):734-54. doi: 10.1128/CMR.00015-11.

*Corresponding author: Dr. Lienda Bashier Eltayeb. Department of Medical Laboratory Science, College of Applied Medical Science, Prince Sattam bin Abdulaziz University, Al-Kharj, Saudi Arabia.E-mail: lindarose009@hotmail.com
7. van den Hoogen BG, de Jong JC, Groen J, Kuiken T, de Groot R, Fouchier RA, Osterhaus AD. A newly discovered human pneumovirus isolated from young children with respiratory tract disease. Nat Med. 2001 Jun;7(6):719-24. doi: $10.1038 / 89098$.

8. Howe M. Australian find suggests worldwide reach for metapneumovirus. Lancet Infect Dis. 2002 Apr;2(4):202. doi: 10.1016/s1473-3099(02)00257-8.

9. Peret TC, Boivin G, Li Y, Couillard M, Humphrey C, Osterhaus AD, Erdman DD, Anderson LJ. Characterization of human metapneumoviruses isolated from patients in North America. J Infect Dis. 2002 Jun 1;185(11):1660-3. doi: $10.1086 / 340518$.

10. Zhu RN, Qian Y, Deng J, Wang F, Hu AZ, Lu J, Cao L, Yuan Y, Cheng HZ. [Human metapneumovirus may associate with acute respiratory infections in hospitalized pediatric patients in Beijing, China]. Zhonghua Er Ke Za Zhi. 2003 Jun;41(6):441-4. [Article in Chinese].

11. Darniot M, Petrella T, Aho S, Pothier P, Manoha C. Immune response and alteration of pulmonary function after primary human metapneumovirus (hMPV) infection of BALB/c mice. Vaccine. 2005 Aug 22;23(36):4473-80. doi: 10.1016/j.vaccine.2005.04.027.

12. Tarig AGA, Salmo N, Bayati AH. Seroprevalence of Anti-Human Metapneumovirus Antibodies in Hospitalized Children in Sulaimani City/Iraq. Microbiology Research Journal International.2014;4(12):1325-34. https://doi. org/10.9734/BMRJ/2014/11658.

13. Brook I, Windle ML, Barton LL, Rauch D, Steele R. Human Metapneumovirus. Pediatr Infect Dis. 2002;10:15-18 14. Maggi F, Pifferi M, Vatteroni M, Fornai C, Tempestini E, Anzilotti S, Lanini L, Andreoli E, Ragazzo V, Pistello M, Specter S, Bendinelli M. Human metapneumovirus associated with respiratory tract infections in a 3-year study of nasal swabs from infants in Italy. J Clin Microbiol. 2003 Jul;41(7):298791. doi: 10.1128/jcm.41.7.2987-2991.2003.

15. Peiris JS, Tang WH, Chan KH, Khong PL, Guan Y, Lau YL, Chiu SS. Children with respiratory disease associated with metapneumovirus in Hong Kong. Emerg Infect Dis. 2003 Jun;9(6):628-33. doi: 10.3201/eid0906.030009.

16. van den Hoogen BG, van Doornum GJ, Fockens JC, Cornelissen JJ, Beyer WE, de Groot R, Osterhaus AD, Fouchier RA. Prevalence and clinical symptoms of human metapneumovirus infection in hospitalized patients. J Infect Dis. 2003 Nov 15;188(10):1571-7. doi: 10.1086/379200.

17. Williams JV, Wang CK, Yang CF, Tollefson SJ, House FS, Heck JM, Chu M, Brown JB, Lintao LD, Quinto JD, Chu D, Spaete RR, Edwards KM, Wright PF, Crowe JE Jr. The role of human metapneumovirus in upper respiratory tract infections in children: a 20-year experience. J Infect Dis. 2006 Feb 1;193(3):387-95. doi: 10.1086/499274.

18. Jartti T, van den Hoogen B, Garofalo RP, Osterhaus $\mathrm{AD}$, Ruuskanen $\mathrm{O}$. Metapneumovirus and acute wheezing in children. Lancet. 2002 Nov 2;360(9343):1393-4. doi: 10.1016/ S0140-6736(02)11391-2.

19. Esper F, Boucher D, Weibel C, Martinello RA, Kahn JS. Human metapneumovirus infection in the United States: clinical manifestations associated with a newly emerging respiratory infection in children. Pediatrics. 2003 Jun;111(6 Pt 1):1407-10. doi: 10.1542/peds.111.6.1407.

20. van den Hoogen BG, Osterhaus DM, Fouchier RA. Clinical impact and diagnosis of human metapneumovirus infection. Pediatr Infect Dis J. 2004 Jan;23(1 Suppl):S25-32. 
doi: 10.1097/01.inf.0000108190.09824.e8.

21. Williams JV, Harris PA, Tollefson SJ, Halburnt-Rush LL, Pingsterhaus JM, Edwards KM, Wright PF, Crowe JE Jr. Human metapneumovirus and lower respiratory tract disease in otherwise healthy infants and children. N Engl J Med. 2004 Jan 29;350(5):443-50. doi: 10.1056/NEJMoa025472.

22. Boivin G, De Serres G, Côté S, Gilca R, Abed Y, Rochette L, Bergeron MG, Déry P. Human metapneumovirus infections in hospitalized children. Emerg Infect Dis. 2003 Jun;9(6):63440. doi: 10.3201/eid0906.030017.

23. Mullins JA, Erdman DD, Weinberg GA, Edwards K, Hall CB, Walker FJ, Iwane M, Anderson LJ. Human metapneumovirus infection among children hospitalized with acute respiratory illness. Emerg Infect Dis. 2004 Apr;10(4):700-5. doi: 10.3201/eid1004.030555.

24. Ulloa-Gutierrez R, Skippen P, Synnes A, Seear M, Bastien N, Li Y, Forbes JC. Life-threatening human metapneumovirus pneumonia requiring extracorporeal membrane oxygenation in a preterm infant. Pediatrics. 2004 Oct;114(4):e517-9. doi: 10.1542/peds.2004-0345.

25. Schildgen O, Glatzel T, Geikowski T, Scheibner B, Matz B, Bindl L, Born M, Viazov S, Wilkesmann A, Knöpfle G, Roggendorf M, Simon A. Human metapneumovirus RNA in encephalitis patient. Emerg Infect Dis. 2005 Mar;11(3):46770. doi: 10.3201/eid1103.040676.

26. Centers for Disease Control [CDC]. Specimen collection guidelines. https://www.cdc.gov/urdo/downloads/ speccollectionguidelines.pdf

27. Wang X, Zhang Q, Zhang F, Ma F, Zheng W, Zhao Z, Bai $\mathrm{Y}$, Zheng L. Visual detection of the human metapneumovirus using reverse transcription loop-mediated isothermal amplification with hydroxynaphthol blue dye. Virol J. 2012 Jul 27;9:138. doi: 10.1186/1743-422X-9-138.

28. Mackay IM, Jacob KC, Woolhouse D, Waller K, Syrmis MW, Whiley DM, Siebert DJ, Nissen M, Sloots TP. Molecular assays for detection of human metapneumovirus. J Clin Microbiol. 2003 Jan;41(1):100-5. doi: 10.1128/jcm.41.1.100-105.2003.

29. Døllner H, Risnes K, Radtke A, Nordbø SA. Outbreak of human metapneumovirus infection in Norwegian children. Pediatr Infect Dis J. 2004 May;23(5):436-40. doi: 10.1097/01. inf.0000126401.21779.74.

30. McAdam AJ, Hasenbein ME, Feldman HA, Cole SE, Offermann JT, Riley AM, Lieu TA. Human metapneumovirus in children tested at a tertiary-care hospital. J Infect Dis. 2004 Jul 1;190(1):20-6. doi: 10.1086/421120.
31. Yi L, Zou L, Peng J, Yu J, Song Y, Liang L, Guo Q, Kang M, Ke C, Song T, Lu J, Wu J. Epidemiology, evolution and transmission of human metapneumovirus in Guangzhou China, 2013-2017. Sci Rep. 2019 Oct 1;9(1):14022. doi: 10.1038/s41598-019-50340-8.

32. Yahia S, Kandeel AY, Hammad E, El-Gilany AH. Human metapneumovirus (hMPV) in acute respiratory infection: a clinic-based study in Egypt. Indian J Pediatr. 2012 Oct;79(10):1323-7. doi: 10.1007/s12098-011-0677-5.

33. Ji W, Wang Y, Chen Z, Shao X, Ji Z, Xu J. Human metapneumovirus in children with acute respiratory tract infections in Suzhou, China 2005-2006. Scand J Infect Dis. 2009;41(10):735-44. doi: 10.1080/00365540903148264.

34. Papenburg J, Hamelin MÈ, Ouhoummane N, Carbonneau J, Ouakki M, Raymond F, Robitaille L, Corbeil J, Caouette G, Frenette L, De Serres G, Boivin G. Comparison of risk factors for human metapneumovirus and respiratory syncytial virus disease severity in young children. J Infect Dis. 2012 Jul 15;206(2):178-89.

35. Zhang C, Du LN, Zhang ZY, Qin X, Yang X, Liu P, Chen X, Zhao Y, Liu EM, Zhao XD. Detection and genetic diversity of human metapneumovirus in hospitalized children with acute respiratory infections in Southwest China. J Clin Microbiol. 2012 Aug;50(8):2714-9. doi: 10.1128/JCM.00809-12.

36. Wei HY, Tsao KC, Huang CG, Huang YC, Lin TY. Clinical features of different genotypes/genogroups of human metapneumovirus in hospitalized children. J Microbiol Immunol Infect. 2013 Oct;46(5):352-7. doi: 10.1016/j. jmii.2012.07.007.

37. Heikkinen T, Osterback R, Peltola V, Jartti T, Vainionpää R. Human metapneumovirus infections in children. Emerg Infect Dis. 2008 Jan;14(1):101-6. doi: 10.3201/eid1401.070251.

38. Zou LR, Mo YL, Wu D, Fang L, Li H, Chen QX, Huang P, Deng XL, Ke CW. [Investigation of human metapneumovirus in children with acute respiratory tract infections in Guangzhou areas]. Zhonghua Yu Fang Yi Xue Za Zhi. 2009 Apr;43(4):3148. [Article in Chinese].

39. Reina J, Ferrés F, Mena A, Figuerola J, Alcoceba E. Características clínicas y epidemiológicas de las infecciones respiratorias causadas por el metapneumovirus humano en pacientes pediátricos [Clinical and epidemiological characteristics of respiratory infections caused by human metapneumovirus in pediatric patients]. Enferm Infecc Microbiol Clin. 2008 Feb;26(2):72-6. doi: 10.1157/13115540. [Article in Spanish]. 